\title{
Spectrophotometric Determination of Mercury (II) By Simultaneous Micelle Mediated Extraction Through Ternary Complex Formation in Water Samples
}

\section{FARZIN NEKOUEI* and SHAHRAM NEKOUEI}

Young Researchers and Elite Club, Gachsaran Branch, Islamic Azad University, Gachsaran, Iran.

http://dx.doi.org/10.13005/ojc/300266

(Received: March 13, 2014; Accepted: May 04, 2014)

\begin{abstract}
In this study, a micelle mediated extraction procedure for preconcentration of trace quantities of $\mathrm{Hg}$ (II) as a prior step to its simultaneous spectrophotometric determination has been developed. The method is based on a ternary ion-association of $\mathrm{Hg}(\mathrm{II})$, Xylidyl Blue (XB) and cationic surfactant (CTAB). Major factors affecting the efficiency of the method has been studied. The limit of detection (LOD) under optimum conditions based on $3 \mathrm{~S}_{\mathrm{b}}$ was $4.65 \mathrm{ng} \mathrm{mL}^{-1}$. The proposed method has been applied for determination of trace amount of mercury in water samples with satisfactory results.
\end{abstract}

Key words: $\mathrm{Hg}(\mathrm{II})$, Xylidyl Blue, cloud point extraction (CPE), Ternary ion-association system.

\section{INTRODUCTION}

Nowadays, in such an industrial world one of the most important concerns is securing the health of human race. The harmful effects of mercury and organomercury species are well known. Disastrous effects, both on personal levels and large population levels, have resulted from exposure to certain mercury species. Mercury exists in a variety of inorganic and organic forms. The environmental chemistry of mercury is complex and difficult to predict because it is controlled by a multitude of environmental processes which includes photochemical reactions, chemical oxidation and reduction, microbial transformation, and physiological fractionation leading to complex and highly mobile cycles of transitions between molecular forms, each with varying degrees of toxicity ${ }^{1}$. In aquatic environments, mercury is methylated through a microbially-mediated process primarily involving sulfate-reducing bacteria. Methylmercury is of great concern in aquatic environments because of its ability to bioconcentrate and biomagnify through trophic webs ${ }^{1}$. More direct anthropogenic mercury contributions come from municipal wastewater treatment plants ${ }^{2,3}$ and a number of industrial processes. Chronic exposure to mercury results in toxicity to the central nervous system, and the extensive use of mercury in the fur, felt and hat industry in the eighteenth century was the cause of "mad hatters disease," a condition characterized by delirium and hallucinations ${ }^{4}$. At least two epidemiological studies have linked methylmercury exposure to deaths from leukemia ${ }^{5,6}$. 
Ternary complexes in which the central ion reacts with two different ligands, have aroused considerable interest in the past two decades ${ }^{7,8}$. Ion association systems, in general way, could be said to result from the interaction of charged particles such as metal cations or complexes with oppositely charged ions. In the last decade, the increase of attention and interest upon the use of aqueous micellar solution has been found in field of separation science ${ }^{9}$. The cloud point extraction (CPE) technique has also been applied as a procedure for determination and removal of dyes and pigments as well as analyzing metals ${ }^{10-11}$.

In this work, we have adopted a method for the simultaneous spectrophotometric determination of mercury (II) after preconcentration in a simple cloud point extraction process based on a ternary ion-association of $\mathrm{Hg}(\mathrm{II})$, Xylidyl Blue (XB) and cationic surfactant (CTAB). The method is based on the colour reaction of mercury (II) with Xylidyl Blue (XB) and micelle mediated extraction of produced complexes. A cationic surfactant, cetyltrimethylammonium bromide (CTAB) was chosen as extracting agent.

\section{EXPERIMENTAL}

\section{Apparatus}

Absorption spectra and absorbance measurements were made by a Shimadzu UV-1800, UV-Vis spectrophotometer using $1 \mathrm{~cm}$ quartz cells (1.0 mL). A Metrohm digital pH meter (model 691) with a combined glass electrode was applied to measure $\mathrm{pH}$ values. A Hettich universal 320 centrifuge was used to hasten the phase separation.

\section{Standard solutions and reagents}

Unless otherwise stated, all commercial reagents used were of analytical grades without further purification. The stock solution of $\mathrm{Hg}^{2+}(1000$ $\mu \mathrm{g} \mathrm{mL}^{-1}$ ) was prepared by dissolving suitable amount of $\mathrm{HgCl}_{2}$ in ultrapure water with several drops of concentrated hydrochloric acid $(\mathrm{HCl})$. A working solution was prepared by suitable dilution. A 1.010${ }^{4} \mathrm{~mol} \mathrm{~L}^{-1}$ solution Xylidyl Blue was prepared by dissolving appropriate amount of this reagent (Sigma) in freshly double distillated water and diluting to the mark in a $100 \mathrm{~mL}$ volumetric flask. Stock solution CTAB $\left(1.010^{-3} \mathrm{~mol} \mathrm{~L}^{-1}\right)$ was prepared by dissolving $0.0364 \mathrm{~g}$ of this reagent (Merck) in bidistilled water and diluting to the mark in a 100 $\mathrm{mL}$ volumetric flask. Stock solution of $\mathrm{NaCl}\left(1.010^{-1}\right)$ was prepared by dissolving $0.584 \mathrm{~g} \mathrm{NaCl}$ in distilled water and diluting to $100 \mathrm{~mL}$ in a flask.

\section{Procedure}

An aliquot of the solution containing of $\mathrm{Hg}^{2+}$ (so that its final concentration would be in the range of 20-1000 $\mathrm{g} \mathrm{L} \mathrm{L}^{-1}$ ), $2.0 \mathrm{~mL}$ of $\mathrm{pH} 5.0$ acetate buffer solution, $1.5 \mathrm{~mL}$ of $1.0 \times 10^{-4} \mathrm{~mol} \mathrm{~L}^{-1}$ of $\mathrm{XB}, 2.0 \mathrm{~mL}$ of $1 \times 10^{-3} \mathrm{~mol} \mathrm{~L}^{-1}$ of CTAB, and $1.5 \mathrm{~mL}$ of $110^{-1} \mathrm{~mol} \mathrm{~L}^{-1}$ of $\mathrm{NaCl}$, was transferred into a $25 \mathrm{~mL}$ tube, diluted to the mark with distilled water, allowed to stand for $10 \mathrm{~min}$ at room temperature. Separation of the aqueous and surfactant-rich phase was performed by centrifugation for $10 \mathrm{~min}$ at $3500 \mathrm{rpm}$. Subsequently, the aqueous phase could be discarded by inclining the tube. The surfactant-rich phase of this procedure was dissolved and diluted to $0.8 \mathrm{~mL}$ with the DMF and transferred into a quartz cell $(1 \mathrm{~mL})$. The absorbance of extracted colored ion associate was measured at $523 \mathrm{~nm}$ in 1 $\mathrm{cm}$ cells against a reagent blank.

\section{Preparation of samples}

The water samples including lake water, river water, dental waste water, industrial waste water and domestic waste water were preconcentrated by evaporation. All the collected samples were spiked with a suitable amount of standard solution of $\mathrm{Hg}^{2+}$. All the aforementioned samples were filtered through a $0.22 \mu \mathrm{m}$ membrane to remove the suspended and floated particles.

\section{RESULTS AND DISCUSSION}

To obtain the maximum absorbance and sensitivity, we need to optimize various conditions which can affect the extraction. Hence, the effects of various operating conditions have been investigated and the optimum concentrations have been established for CPE.

\section{Effect of $\mathrm{pH}$}

The $\mathrm{pH}$ plays a crucial role in metalcomplex and ion associated complex formation. Very low and high values of $\mathrm{pH}$ can cause to decompose of ion associated complex formation. The effect of $\mathrm{pH}$ on the extraction efficiency of mercury (100.0 ng $\mathrm{mL}^{-1}$ ) was studied with $\mathrm{pH}$ values varying from 3.0 
to 9.0. As can be seen in Fig.1, the maximum extraction efficiency of mercury was obtained at $\mathrm{pH}$ 5.0. The $\mathrm{pH}$ was adjusted to the desired value using $2 \mathrm{~mL}$ of $\mathrm{pH} 5$ acetate buffer solution.

\section{Effect of Xylidyl Blue dye concentration}

Xylidyl Blue is a dye having heterocyclic azo-group in form of $\mathrm{H}_{2} \mathrm{~L}^{-}$, used as a ligand. It is complexed with the metal ions through the nitrogen atom, the amino-nitrogen atoms and o-hydroxyl groups. In this procedure the XB was used as a chelating agent. The effect of $X B$ concentration used for the determination of $\mathrm{Hg}^{2+}$ was examined by varying the amounts of $X B$. The absorbance increased with increasing $X B$ concentration up to $1.510^{-5} \mathrm{~mol} \mathrm{~L}^{-1}$ of $\mathrm{XB}$ in the final solution and concentrations greater than $1.510^{-5} \mathrm{~mol} \mathrm{~L}^{-1}$ have no effect on the extraction of the mercury. The absorbance changes as a function of the concentration of XB were shown in Fig.2.

\section{Effect of CTAB concentration}

The effect of CTAB concentration used for the extraction of $\mathrm{Hg}^{2+}$ was examined by varying the

Table 1: Determination of $\mathrm{Hg}^{2+}$ in spiked water samples

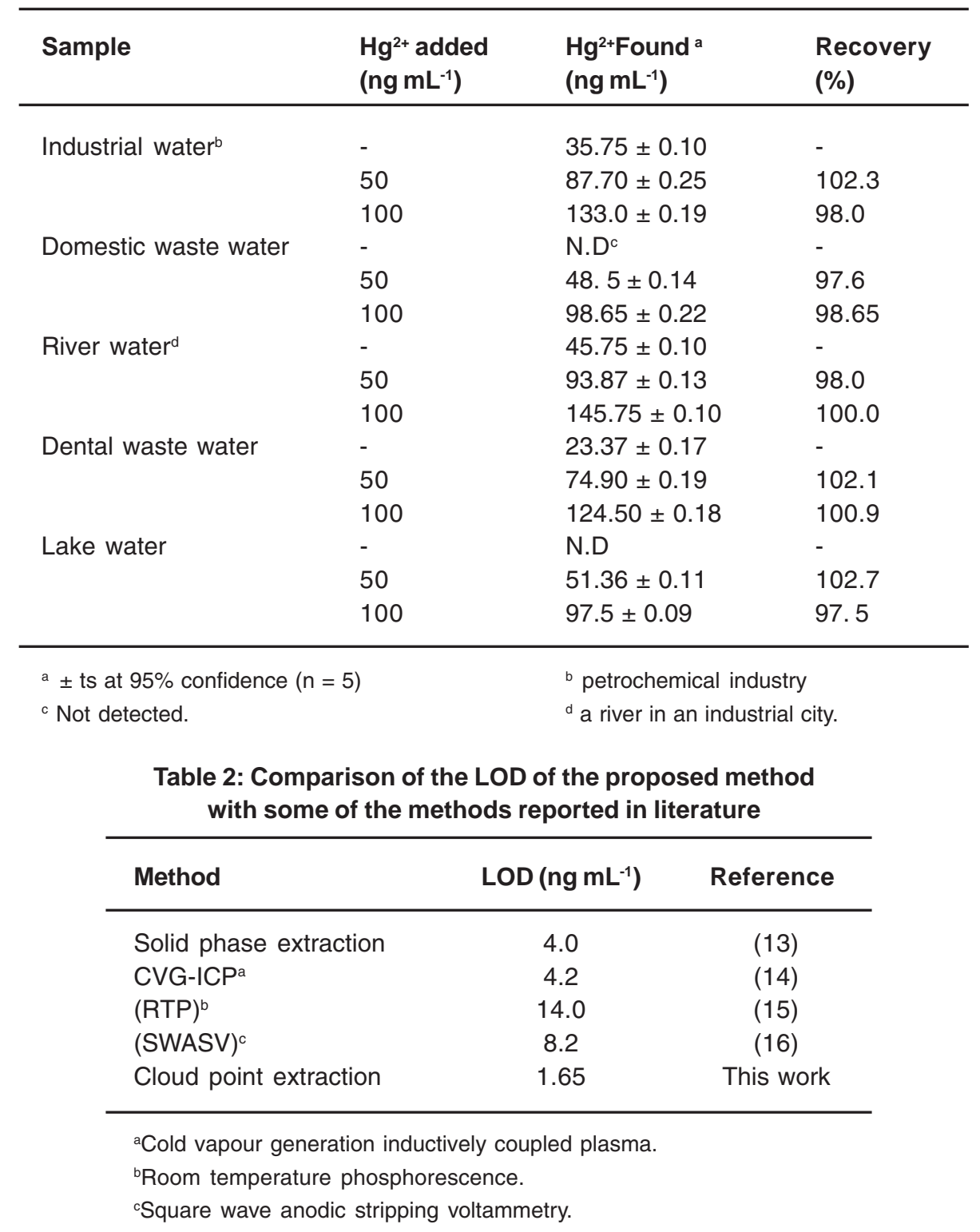


amounts of CTAB surfactant. CTAB is a cationic surfactant that in this procedure the CTAB was used as an extraction agent, which transfers metal-ligand complex from aqueous phase to surfactant-rich phase. The absorbance of ternary ion associate increased with increasing CTAB concentration up to $2.010^{-4} \mathrm{~mol}$

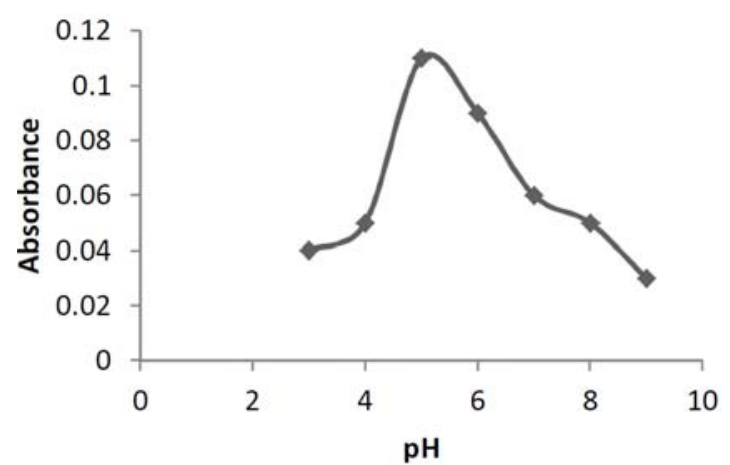

Fig. 1: The effect of $\mathrm{pH}$ on the absorbance of 0.1 $\mu \mathrm{g} \mathrm{mL}^{-1}$ of $\mathrm{Hg}^{2+}$ after micelle mediated extraction

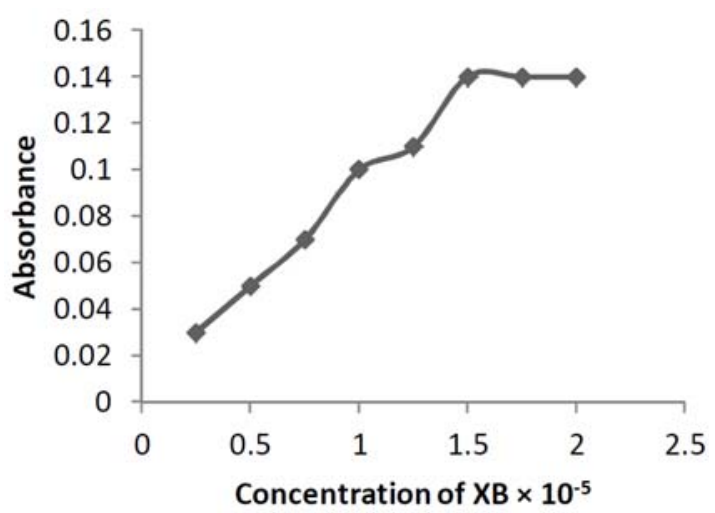

Fig. 2: The effect of $X B$ concentration on the absorbance of $0.1 \mu \mathrm{g} \mathrm{mL}^{-1}$ of $\mathrm{Hg}^{2+}$ after micelle mediated extraction

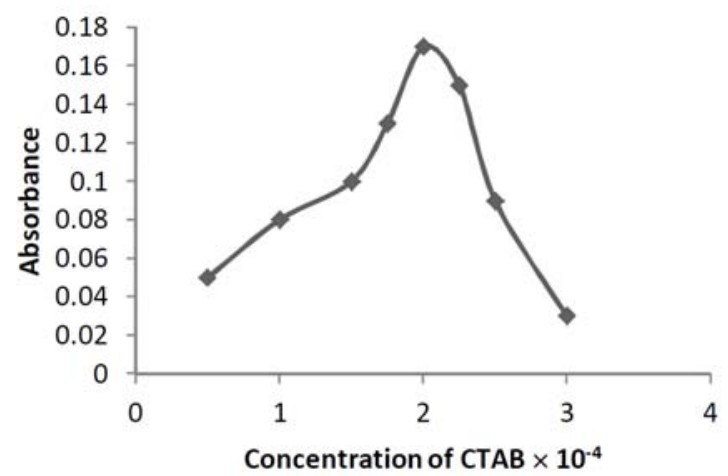

Fig. 3: The effect of CTAB concentration on the absorbance of $0.1 \mu \mathrm{g} \mathrm{mL}^{-1}$ of $\mathrm{Hg}^{2+}$ after micelle mediated extraction
$\mathrm{L}^{-1}$ of $\mathrm{CTAB}$ in the final solution and decreased at more concentrations. The results are shown Fig.3.

\section{Effect of $\mathrm{NaCl}$ concentration}

In this procedure, $\mathrm{NaCl}$ was used as a coextraction agent. The cloud point of micellar solutions can be controlled by addition of alcohols, salts, nonionic surfactants and some organic compounds (salting-out effects) ${ }^{12}$. The effect of electrolyte concentration on the formation of $\left(\mathrm{Hg}^{2+}\right.$-XB)-CTA ${ }^{+}$ ternary ion associate was examined. The result showed that the absorbance of ion association complex increased with increasing $\mathrm{NaCl}$ concentration up to $1.5 \times 10^{-2} \mathrm{~mol} \mathrm{~L}^{-1}$ in final solution and approximately remained constant above that.

\section{Effect of centrifuge time and rate}

It is often necessitated to preconcentrate trace amounts of metals with high efficiency in a minimum time. The results indicated that centrifuging for $10 \mathrm{~min}$ at $3500 \mathrm{rpm}$ leading to the highest extraction of $\mathrm{Hg}^{2+}$. In addition, the effect of time on the formation of $\left(\mathrm{Hg}^{2+}-\mathrm{XB}\right)-\mathrm{CTA}^{+}$ternary ion associate was studied over the time period $5-20$ min which the maximum absorbance was obtained $10 \mathrm{~min}$

\section{Analytical performance}

Under optimum conditions, the analytical performance of the proposed method was studied. The calibration curve was linear in the concentration range of $20-1000 \mathrm{ng} \mathrm{mL}^{-1}$. The regression equation obtained by the least square method is $\mathrm{A}=2.16$ $\times 10^{-3} \mathrm{C}_{\mathrm{Hg}}+1.13 \times 10^{-2}$ for $20-1000 \mathrm{ng} \mathrm{mL}^{-1}$ of $\mathrm{Hg}^{2+}$ with a correlation coefûcient of $0.998(n=15)$, where $A$ is the absorbance and $C_{\mathrm{Hg}}$ shows the concentration of $\mathrm{Hg}^{2+}$ in $\mathrm{ng} \mathrm{mL}^{-1}$. The limit of detection (LOD) based on $3 \mathrm{~S}_{\mathrm{b}}$ was $4.65 \mathrm{ng} \mathrm{mL}^{-1}$ and the relative standard deviation (RSD) at 50 and $500 \mathrm{ng} \mathrm{mL}^{-1}$ was 2.378 and 1.245 , respectively $(\mathrm{n}=$ 8). The preconcentration factor was 31.25.

\section{Interference studies}

In order to study the influence of various cations and anions on the determination of $\mathrm{Hg}^{2+}$, a fixed concentration of $\mathrm{Hg}^{2+}, 100.0 \mathrm{ng} \mathrm{mL}^{-1}$, was taken with different amounts of foreign ions and recommended procedure was followed. A relative error of $\pm 5 \%$ with respect to the absorbance difference for the $\mathrm{Hg}^{2+}$ solution was considered 
tolerable. The result indicated that $\mathrm{Na}^{+}, \mathrm{Cl}^{-}(1000$ folds), $\mathrm{Mn}^{2+}, \mathrm{Li}^{+}, \mathrm{NO}_{3}^{-}$(800 folds), $\mathrm{Ba}^{2+}, \mathrm{CH}_{3} \mathrm{COO}$, $\mathrm{K}^{+}, \mathrm{NH}_{4}^{+}, \mathrm{Ag}^{+}, \mathrm{HCO}_{3}^{-}, \mathrm{Br}, \mathrm{HPO}_{4}^{2-}$ (500 folds ), $\mathrm{Co}^{2+}$, $\mathrm{Zn}^{2+},\left(250\right.$ folds), $\mathrm{Sn}^{2+}, \mathrm{Cd}^{2+}$ (100 folds), $\mathrm{Cu}^{2+}, \mathrm{Pb}^{2+}$, $\mathrm{Al}^{3+}$ (50 folds), did not interfered. This shows the good selectivity of the proposed method.

\section{Application}

The proposed method was applied to the determination of $\mathrm{Hg}^{2+}$ in water samples. The results are shown in Table 1. The validity of the method is satisfactory. The recoveries are nearly close to $100 \%$ and indicate that the proposed method was helpful for the preconcentration and determination purpose. In addition, the analytical performance of the proposed method for extraction and determination of $\mathrm{Hg}^{2+}$ was compared with those of previously reported. A comparison of the results is given in Table 2.

\section{CONCLUSION}

The aim of this study is spectrophotometric determination of Mercury (II) by simultaneous micelle mediated extraction through ternary complex formation in water samples. The proposed method is simple, rapid, reproducible and highly sensitive and can be applied for quality control of $\mathrm{Hg}^{2+}$ in water samples. The limit of detection of the proposed method seems to be satisfactory. Furthermore, in contrast with solvent extraction methods, it is much safer, because only a small amount of the surfactant, which has a low toxicity, is used.

\section{ACKNOWLEDGEMENTS}

The authors gratefully acknowledge the financial support of this work by Young Researchers and Elite Club, Gachsaran Branch, Islamic Azad University, Gachsaran, Iran (Grant 1392).

\section{REFERENCES}

1. Michele Harmon, S. Anthropogenic Mercury Pollution In Aquatic Systems: a Review of Environmental Fate and Human Health Risks. SÁNCHEZ, M. L. (Ed), Causes and Effects of Heavy Metal Pollution, New York: Nova Science Publishers,173, (2008).

2. Glass, G. E.; Sorensen, J. A.; Schmidt, K. W.; Rapp, G. R.; Yap, D.; Fraser, D. Water Air Soil Poll. 1991, 56, 235-249.

3. Hermanson, M. H. Water Air Soil Poll. 1998, 101, 309-321.

4. Goyer, R. A. Toxic effects of metals. Amdur, M. O.; Doull, J.; Klaassen, C. D. (Eds), Casarett and Doull's Toxicology: The Basic Science of Poisons. (4th ed.). New York, NY: McGrawHill, 623, (1993).

5. Janicki, K.; Dobrowolski, J.; Krasnicki, K. Chemosphere, 1987, 16, 253-257.

6. Kinjo, Y.; Akiba, S.; Yamaguchi, N.; Mizuno, S.; Watanabe, S.; Wakamiya, J.; Futatsuka, M.; Kato, H. J. Epidemiol. 1996, 6, 134-138.

7. Nekouei, F.; Parham, H. Asian J. Chem. 2010, 22, 319-324.

8. bdellatef, H. E.; Ayad, M. M.; Taha, E. A. J. Pharmaceut. Biomed. Anal. 1999, 18, 1021-
1027.

9. Gullickson, N. D.; Scamehorn, J. F.; Harwell, J. H. Liquid-coacervate extraction. In: Scamehorn J. F.; Harwell H. J. (Eds), Surfactant Based Separation Processes; Marcel Dekker Inc: New York, 139, (1989).

10. Abedi, Sh.; Nekouei, F. E-J. Chem. 2011, 8, 1588-1595.

11. Mousavi, R.; Nekouei, F. E-J. Chem. 2011, 8, 1606-1613.

12. Nascentes, C. C.; Arruda, M. A. Z. Talanta, 2003, 61, 759-768.

13. Rajesh, N.; Gurulakshmanan, G. Spectrochim. Acta Part A, 2008, 69, 391-395.

14. Kenduzler, E.; Ates, M.; Arslan, Z.; McHenry, M.; Tchounwou, P. B. Talanta, 2012, 93, 404410.

15. De la Riva, B. S. V.; Costa-Fernández, J. M.; Jin, W. J.; Pereiro, R.; Sanz-Medel, A. Anal. Chim. Acta, 2002, 455, 179-186.

16. Afkhami, A.; Madrakian, T.; Sabounchei, S. J.; Rezaei, M.; Samiee, S.; Pourshahbaz, M. Sensor. Actuator. B: Chemical, 2012, 161, 542-548. 